\title{
The Invisible Negotiator in the Land of Paradox Management
}

\author{
Eliane Karsaklian \\ LARGEPA-Université Sorbonne, Paris, France
}

\begin{abstract}
In this paper, the author discusses the importance of the invisible negotiator as an underlying yet neglected concept in the negotiation academic research. The author argues that the existence and the role of the invisible negotiator in China are founded on the paradox management inherent in the Chinese culture. This conceptual paper brings negotiation and paradox management together and states that the existence of paradoxes leads negotiators to neglect features of international negotiations that are not visible because they seem to be inconsistent with the prevalent models of cultural analysis. Researchers and negotiators need to move away from binary cultural frameworks and embrace paradoxes as a natural feature of all cultures in order to understand hidden actors in negotiations. After reading this paper, negotiators will have more holistic and balanced view of other cultures when understanding and referring to paradox management because a better understanding of cultural characteristics can lead to less conflicts and better business across cultures. To our best knowledge, no previous researches have revealed the existence of invisible negotiators due to paradox management.
\end{abstract}

Keywords: international negotiation, China, cultural frameworks, paradox management, negotiation strategies

The difficulties in negotiating with the Chinese are clearly expressed by Western negotiators in a number of publications: "Chinese negotiators are immoral business people who cheat, lie or do whatever is necessary to throw you off balance" (Fang, 2006). "Bargaining never stopped after the original agreement was signed and business actually started" (Eiteman, 1990). "The Chinese make sudden demands or changes to put Western teams in a disadvantageous position" (Stewart \& Keown, 1989). "China is possibly the toughest business environment in the world because of the enormous intricacy and competitive intensity of the culture. In China, honesty is paramount only among members of closely-knit in-groups, while engaging in deception to obtain advantage is seen as acceptable conduct" (Shi \& Wright, 2003). "We know that management practice in China can be difficult and that foreign companies do leave in frustration" (Walsh, Wang, \& Xin, 1999). "Negotiating with the Chinese can be a daunting challenge to foreign businesspeople given the complex cultural roots of the Chinese negotiation style" (Tian, 2007).

The quotes above, excerpted from interviews in previous researches, are common to disrupted negotiators from abroad when working with the Chinese. Surprises, disappointments, and frustration often seem to be inherent in any business that Westerners do with the Chinese because China is a special challenge (Ghauri \& Fang, 2001). Indeed, the continuous back-and-forth bargaining feature in the Chinese negotiating style (Ghauri \& Fang, 2001) can be highly disturbing to Westerners working with them.

These characteristics of the Chinese negotiating style are perceptible by the non-Chinese negotiators

Corresponding author: Eliane Karsaklian, Ph.D., professor at Sorbonne University, director, Master's degree in International Negotiation, LARGEPA-Sorbonne, Paris, France; research fields: international business, international negotiation, international marketing, and intercultural management. 
although they cannot always explain the reasons for such behaviours. Presumably, what is not perceptible to the non-Chinese senses is the existence of the invisible negotiator. The invisible negotiator plays a key role in every kind of negotiation in China, no matter what the object of the negotiation is and what is at stake. It can be as banal as a traffic accident (Faure, 1995) or as complex as an international joint venture. The negotiation process is the same. The sociological approach to understanding the role of the invisible negotiator in China has not been largely discussed in academic research and few descriptions and explanations of it as a phenomenon inherent in the Chinese culture are found in literature (Faure, 1995).

Admittedly, the ability the Chinese have to manage paradoxes is an essential cultural trait driving negotiation dynamics and the author's main purpose is to capture the essence of negotiation in China using this prism. To do so, this paper seeks to uncover a critical specificity of the Chinese culture in the negotiation process. This specificity has been "invisible" to most non-Chinese negotiators and researchers so far because the majority of literatures on Chinese-Western cultural differences and the Chinese negotiation style have relied on a limited number of frameworks. The author acknowledges that static and polarized non-contradictory classifications of cultural dimensions, also called "either/or" (G. Hofstede \& G. J. Hofstede, 2005; Hofstede, 1984; Trompenaars \& Hampden-Turner, 2006; Lewis, 2006; 2012; Hall, 1976), provide general methodological advantages for cultural analysis, however, they carry a risk of missing "both/and" diversity within culture (Fang, 2014; 2011; 2010; 2006; 2003; 1999; Fang, Worm, \& Tung, 2008; Fang \& Faure, 2011; Faure \& Fang, 2008; Faure, 1995; Chen, 1987; Chen, 2001; Chen \& Starosta, 1997; Chen, 2002; Ghauri \& Fang, 2001; Shi \& Wright, 2003). It is the absence of this "both/and" prism that has led to the lack of attention to the role and importance of the invisible negotiator. Using this prism for interpretation of the Chinese culture, the author views the existence and the role of the invisible negotiator as a natural expression of this worldview where everything embraces opposite properties (Fang, 2003). If China is seen as a country where paradoxes are interdependent and seek mutual harmony ( $\mathrm{Li}, 2012 ; 2014 ; 2016$ ), then the invisible negotiator is the personification of this cultural trait. His role is to find common interest between opposed parties and help them get to an agreement without being officially part of the team of negotiators.

In this paper, the author discusses the importance of the invisible negotiator as an underlying yet neglected concept in the negotiation academic research. The author defines invisible negotiator as the one who brings people together and helps "visible" negotiators to find common ground and succeed in their negotiations. The author admits that in all cultures there are invisible actors involved in a negotiation however the specific traits of the Chinese invisible negotiator are rooted in paradox management.

Fisher and Ury (2011) described negotiation as a basic means of getting what we want from others. When people differ, they use negotiation to handle their differences. Cellich and Jain (2003) defined negotiation as a process by which two or more parties reach agreement on matters of common interest. Lewicki et al. (2011), stated that goals are the focus that drives a negotiation strategy. Determining the negotiation goals is the very first step in developing and executing a negotiation strategy.

Although the scientific validity of the above definitions is not questionable, they do not capture the complexity of the Chinese paradoxical negotiation style. For instance, Cellich and Jain (2003) did not mention the invisible negotiator among the parties involved in a negotiation although his intervention is critical to the Chinese negotiations. Literature on negotiation in China discusses concepts such as reliance on relationships, prevalence of moral over legal principles, and importance of hierarchy and face, and is thus based on Western cultural frameworks (Chuah, Hoffman, \& Larner, 2014; Osman-Gani \& Tan, 2002; Shi \& Wright, 2003; 
Bhattacharjee \& Zhang, 2011; Leung, Chan, Lai, \& Ngai, 2011; Rivers, 2009). Additional studies have focused on differences between American and Chinese negotiating styles as antipodes, interpreting them on a scale of individualist versus collectivistic; egalitarian versus hierarchical; task versus relationship oriented; and sequential versus circular (Walsh et al., 1999; Palich, Carini, \& Livingstone, 2002; Cardon, 2009; Eiteman, 1990).

As stated in previous research (Li, 2016; 2014; 2012; Li, Leung, Chen, \& Luo, 2012; Fang, 2014; 2011; 2010; 2006; 2003; 1999; Fang et al., 2008; Fang \& Faure, 2011; Faure \& Fang, 2008; Faure, 1995; Chen, 1987; Chen, 2001; Chen \& Starosta, 1997; Chen, 2002; Ghauri \& Fang, 2001; Shi \& Wright, 2003), Western models of cultural dimensions are limited in capturing the essence of the Chinese culture and value system, symbolized in the mutually opposed yet complementary forces of Yin and Yang viewed in the Chinese tradition as the opposites contained in one another, forming together an ever-changing, harmonious unity. In particular, the traditional Western cultural dimension approach is not suitable for understanding the paradoxical and changing character of the Chinese negotiation style as a reflection and expression of their value system.

As an underlying driving force in the negotiation process, the invisible negotiator is the embodiment of the inherent Chinese cultural tendency to manage paradoxes. It is geared towards finding a compromise and with clear separation from standard negotiation understood as being the interaction between sellers and buyers. The Yin Yang approach reflects the process of change as a fundamental principle of the universe (Fang, 1999; 2006; 2014; Li, 2012; 2014; 2016) and much like the perpetual interaction and complementarity between Yin and Yang, the process of paradox management and negotiation is circular in China.

Same complementarity is aimed by the invisible negotiator whose role is to bring all parties together by fulfilling their respective requirements, needs, and goals. Indeed, the invisible negotiator is not clearly identified as a negotiator participating in the negotiation process and his approach is not based on straight talking, on facts and figures, and on direct questioning. Au contraire, his approach is subtle and circular whereby he centrifuges all parties in a whirl of thoughts, events, and opinions until an agreement is reached. Unlike the parties involved in the negotiation who focus on achieving their goals, the invisible negotiator assumes a holistic and systemic approach to the negotiation process. The invisible negotiator takes distance from the problematized negotiation, assesses incompatible interests and goals, and finds a way of articulating them towards an agreement.

In other terms, the invisible negotiator shifts the negotiation process from "either/or" (G. Hofstede \& G. J. Hofstede, 2005; Hofstede, 1984; Trompenaars \& Hampden-Turner, 2006; Lewis, 2006; 2012; Hall, 1976) and "both/and" (Fang, 2014; 2011; 2010; 2006; 2003; 1999; Fang et al., 2008; Fang \& Faure, 2011; Faure \& Fang, 2008; Chen, 2002) paradigms to an "either/and" framework (Li, 2012; 2014; 2016; Li et al., 2012). That is to say that the role of the invisible negotiator is to bring negotiators together, despite their differences and integrate their goals and interests into a deal that makes them succeed in a negotiation instead of focusing on winning or losing the negotiation.

As a matter of fact, win-lose can be assimilated to the "either/or" paradigm — a negotiator "either" wins "or" loses the negotiation, while win-win paradigm can be assimilated to the "both/and" paradigm — both negotiators win the negotiation. The understanding of international negotiation is that winning and losing are not appropriate terms for a professional aiming at working together. Succeeding in international negotiation is integrating different goals, strategies, and cultures into a working frame that enables negotiators to create a common vision of the negotiation outcomes. 


\section{The Old and New Paradigms in International Negotiations}

Fisher and Ury's best seller, Getting to yes (1981), established a paradigm that has been ruling the Western negotiating style up until international negotiation developed across borders and interactions became less unilateral. Rather than flowing from the United States towards the rest of the world, international negotiations are now held between countries from West and East. Coincidentally, cultural frameworks having emerged from the West around the same period (Hofstede, 1984; Hall, 1976; G. Hofstede \& G. J. Hofstede, 2005; Trompenaars \& Hampden-Turner, 2006; Lewis, 2006; 2012) also predominated in the Western parts of the world and similar to Fisher and Ury's teachings which were spread out to Eastern countries as if they were universal.

These paradigms were appropriate while the economic power remained concentrated in Northern and Western countries such as the United States and Europe. With the shift to Eastern and Southern economic growth triggered by the BRIC-Brazil, Russia, India, and China, in the late 1990's, researchers from these emerging markets became cognizant of the limits of the predominant Western paradigms to explain their cultures and help negotiators to work together in cross-cultural settings. China turned into the most powerful emerging economy and Western negotiators started to experience difficulties in working with the Chinese. The limits of the so far predominant Western negotiating strategies and cultural dimensions became apparent. This trend became even more visible thanks to prominent Chinese researchers who propose new theories to understand the specificities of the Chinese culture (Li, 2012; 2014; 2016; Li et al., 2012; Fang, 2014; 2011; 2010; 2006; 2003; 1999; Fang et al., 2008; Fang \& Faure, 2011; Faure \& Fang, 2008; Faure, 1995; Chen, 1987; Chen, 2001; Chen \& Starosta, 1997; Chen, 2002; Ghauri \& Fang, 2001; Shi \& Wright, 2003).

In this paper, the author proposes a paradigm shift for both negotiation strategies and cultural frameworks in taking the Chinese invisible negotiator as the embodiment of the need for a better understanding of the Chinese specific cultural traits and the urgency of a paradigm shift in negotiation and cultural understanding. In an attempt to illustrate the author's statement, she will confront some teachings from the prevailing negotiation paradigms with the Chinese culture in the following paragraphs.

Following up on their first book, Fisher and Ury (2011, p. 23) advised to disentangle the relationship with the substance:

Dealing with a substantive problem and maintaining a good relationship need not to be conflicting goals if the parties are committed and psychologically prepared to treat each separately on its own legitimate merits. Base the relationship on mutually understood perceptions, clear two-way communication, expressing emotions without blame and a forward-looking, purposive outlook.

The advices stated above are opposed to everything that the Chinese culture represents. "Disentangling" is opposed to the Chinese who have an integrated and holistic approach to life and business; having both parties agreeing in treating each separately, which does not make any sense in a culture where Yin and Yang are the basis of every belief and action. Furthermore, a clear two-way communication with emotions being expressed is inconsistent with the Chinese subtle communicating style and inexpressiveness as a way of saving face.

Fisher and Ury (2011, p. 27) also advised to deal with differing perceptions by making them explicit and discussing them with the other side. Anyone who has already worked with the Chinese knows that this is just impossible to obtain from them. The author suggests that negotiators make emotions explicit in addressing their counterparts in the following terms (Fisher \& Ury, 2011, p. 33): 
It does not hurt to say: You know, the people on our side feel we have been mistreated and are very upset. We're afraid an agreement will not be kept even if one is reached (...). Do the people on our side feel the same way?

The author states that "Making your feelings or theirs an explicit focus of discussion will not only underscore the seriousness of the problem, it will also make the negotiations less reactive and more 'pro-active"'.

The Western negotiators applying this type of advice when negotiating with the Chinese might be surprised with the opposed effect that their explicitness will have over their Chinese counterparts and how much this loss of face will be a hampering block to get to a deal. Most probably, the negotiation will go nowhere.

Notwithstanding, the merit of principled negotiation as stated by Fisher and Ury is to move negotiators from the traditional assertive win-lose perspective based on goals to a win-win approach based on interests. Yet, in this paper, the author argues that winning and losing are inappropriate to negotiations in general and to the Chinese negotiating style in particular. There is much more behind the Chinese vision of negotiation than winning and losing and this is why negotiating with the Chinese is so disruptive to Western negotiators who are unable to see beyond the win-win and win-lose paradigms.

\section{International Negotiation and Cultural Paradoxes}

Culture influences negotiation on several levels: individual or team negotiation, the amount of time needed to reach an agreement, the value of concessions, the amount of social life integrated in the negotiation process, the influence of family, and risk taking, just to name a few (for a more comprehensive presentation of the impact of culture on international negotiation see Karsaklian, 2014).

Negotiating with the Chinese seems to be "'tricky' to the non-Chinese negotiators because they are immoral, and can cheat and lie or do whatever necessary to knock you out of balance" (Fang, 1999, p. 15). Fang states that the Chinese negotiator can be "both" a sincere "and" a deceptive negotiator and it is disappointing that cultural frameworks have been unable to help understand the mechanisms underlying the complex personality of the Chinese negotiator. The difficulties experienced by Western negotiators are caused by their inability to understand why the Chinese have such an inconsistent behavior. Seen from outside, people "either" love "or" hate China and the Chinese "both" at personal "and" professional levels. It is unacceptable to Westerners that people can be "both" welcoming "and" hostile, "both" protracted "and" quick, "both" lawful "and" unlawful at the same time. Western patterns suppose bi-polar standards of constant linear behavior without taking context into account. On the Chinese side, context is what determines behavior (Li, 2012; 2014; 2016; Li et al., 2012; Fang, 2014; 2011; 2010; 2006; 2003; 1999; Fang et al., 2008; Fang \& Faure, 2011; Faure \& Fang, 2008; Faure, 1995; Chen, 1987; Chen, 2001; Chen \& Starosta, 1997; Chen, 2002; Ghauri \& Fang, 2001; Shi \& Wright, 2003).

In context, the Chinese are paradoxical. Paradox is defined as "contradictory yet interrelated elements that seem logical in isolation but absurd and irrational when appearing simultaneously" (Lewis, 2000, in: Fang, 2006, p. 760; Li, 2016, p. 4). The paradoxical roots of the Chinese culture are originated on the fundamental philosophical traditions regulating the Chinese lives-Confucianism, Taoism, and Buddhism. The ability the Chinese have to articulate three complementary philosophies, explains their pragmatic way of handling paradoxes with mastery (Fang, 1999). The Chinese do not select one of these philosophies to follow as Westerners do with religions; they select the most appropriate features of each one of them and mix them to 
provide themselves with a better life. As a result, Westerners often get confused with the Chinese double-standards which can often be explained by bureaucracy and hierarchy. The Chinese can appear "both" stubborn "and" accommodating during negotiations depending on the (invisible) directions received from their superiors and thanks to that, they have this ability of negotiating "both" internally "and" externally simultaneously (Fang, 1999).

As paradoxical propensities coexist in China (Faure \& Fang, 2008), China's cultural evolution entails the combination of old traditional Chinese values with modern behavior (Li, 2012; 2014; 2016; Li et al., 2012; Fang, 2014; 2011; 2010; 2006; 2003; 1999; Fang et al., 2008; Fang \& Faure, 2011; Faure \& Fang, 2008; Faure, 1995; Chen, 1987; Chen, 2001; Chen \& Starosta, 1997; Chen, 2002; Ghauri \& Fang, 2001; Shi \& Wright, 2003). More specifically and as stated by Chen (2002), the word "middle" implies a harmonious integration of opposites rather than a reactive compromise between them. The Chinese believe that all things in the universe contain competing tendencies that must be balanced and life handled thanks to the ability of balancing these extremes, thus opposite elements constitute an integrated paradoxical framework. The Chinese civilization is a matrix of paradoxical cultural development. The most important characteristic of the Chinese culture is its capacity to produce development, coherence, and consistency out of instability, chaos, and contradiction.

Mervin's culture heritage hypothesis revealed that differences in values drive variances in behaviour, seeing Western way as grounded in use of analytical thinking as a methodology of solving complex problems by breaking them down into their constituent parts (Chen, 2002). This is to distinguish from the Chinese approach that focuses on the relationship between individual elements rather than the elements themselves. Because interaction is the main feature of any relationship, the process is inevitably ongoing as relationships evolve in time. Thus, the invisible negotiator often struggles to bring together different types of logics. Whereas formal logic explicitly refutes the legitimacy of contradictions, dialectic logic takes a perspective that embraces paradox and contradiction through which positive change and growth occur (Palich et al., 2002). Change is motivated by the internal tension between two opposing forces, and consequently, the absence of internal contradiction results in a lack of movement and thus of evolution. In the dialectic logic of the Chinese, the negotiation process is ongoing because the mere existence of paradoxes is embraced, as is their complementarity, whereas the Western thinking pattern has often been characterized as linear and formal logic (Nakamura, 1964).

Knowing that the Chinese have a holistic and systemic approach of things, it is understandable, however disruptive to Westerners, that the Chinese can pick both negotiating strategies within a system and depend on the context as per their analysis of the impact and consequences of what they do on themselves and on their groups. While Western analytical thinking is based on breaking the whole into parts (Chen, 2002), the Chinese mindset takes an integrative point of view in considering all things in terms of their relationships at all levels. To the Chinese, "integration is not a sum or combination of parts, a paradigm grounded in Western philosophy. Rather, it is the totality of relationships which blends all parts together" (Chen, 2002, p. 180).

In addition, the Confucian aversion to law makes the Chinese look unlawful during negotiations because they prioritize sincerity, credibility, and personal commitment over legal considerations (Fang, 1999). The Confucian mindset puts emphasis on personal integrity and the consequent feeling of shame and saving face, which are independent on law. Cultural and social values taught by Confucianism make the Chinese appear as skillful negotiators, however, Fang insists that it is not a matter of negotiation strategies and tactics but mainly of the sense of face and consensus-reaching efforts. Acting as an invisible knife (Fang, 1999, p. 150), saving 
face makes the Chinese look like dishonest people unable to clearly state their opinions and point of views and unable to be factual. Not displaying any emotions is disturbing to Westerns who often misinterpret their inexpressiveness. This only adds to the belief that the Chinese are insincere and they withhold important information.

The paradoxical Chinese approach to business is also visible in the way that different authors described their negotiating style based on Western patterns. Some state that the Chinese practice win-win negotiation while others are convinced that all the Chinese negotiations lead to win-lose outcomes (Fang, 1999). This perception of the Chinese negotiating style is enhanced by their ability to bargain without bargaining (Fang, 1999). The visible negotiators might not bargain openly and wait until the invisible negotiator creates a favorable context for the negotiators to kindly ask for some other concessions, without making it appear as bargaining.

Ultimately, the Chinese are comfortably managing what the non-Chinese avoid, that is, contradictions. To the Chinese, contradictions are not only part of life, but are also and mainly enriching opportunities. The Chinese concept of life and business is bringing the opposites together and understanding that the opposites are interdependent and complementary rather than mutually exclusive (Li, 2012; 2014; 2016; Li et al., 2012; Fang, 2014; 2011; 2010; 2006; 2003; 1999; Fang et al., 2008; Fang \& Faure, 2011; Faure \& Fang, 2008; Faure, 1995; Chen, 1987; Chen, 2001; Chen \& Starosta, 1997; Chen, 2002; Ghauri \& Fang, 2001; Shi \& Wright, 2003). From a non-Chinese point of view, contradictions are to be avoided because inconsistency is dissonant and represents a discomfort detrimental to negotiation. As a matter of fact, in binary and linear cultures, consistency is a quality people should nurture and inconsistencies are to be avoided because they affect trustworthiness. Briefly said, contradictions are opposed to reliability. To the Chinese, contradictions and reliability coexist because opposites attract each other and thus need each other to build something meaningful, reflecting the philosophy of Yin and Yang.

\section{Negotiation as a Never-Ending Process}

Negotiating with the Chinese is often disruptive to Western culture negotiators because they cannot understand the impact of contextual factors (Fang, 2006; Stewart \& Keown, 1989; Shi \& Wright, 2003; Walsh et al., 1999; Tian, 2007; Ghauri \& Fang, 2001). Chinese negotiators are often accused of reviewing contracts' clauses or coming back on their words (Eitman, 1990). However, thoughts and actions deemed inconsistent in binary cultures ("either/or") are just natural in non-binary ("both/and") cultures. The Chinese do not make definite choices - decisions evolve, gradually, with the needs created by the context.

While to Western cultures, ambiguity and vulnerability are seen as a liability, the Chinese dialectical logic accepts that the process unfolds over time and China represents a perfect example of developmental change not only thanks to its language's flexibility which is contextual and thus appropriate to constantly negotiate according to the context (Fang, 1999); but also and mainly because, to the Chinese, there is not a "real end" to anything. Just like Yin and Yang, evolution and movement are constant and critical to keep balance. Indeed, without a clear-cut end to a negotiation in China, the process keeps evolving and transforming the relationship throughout the time. To the Chinese, everything is susceptible to be negotiated all the time. It is highly disruptive to Western counterparts aiming at signing a deal (Graham \& Hernandez Requejo, 2009; Saee, 2008).

This is one of the main reasons why international negotiation is more complex. While Western cultures conform to their short-term clear-cut references and strategies and appreciate the end of the negotiation once 
something is signed; to the Chinese, the negotiation keeps going after a deal has been signed even if it might look like they keep "renegotiating" the terms they had already agreed upon. In reality, the Chinese are not "renegotiating"; they are "still" negotiating. Admittedly, the Chinese evolve around the idea of harmony and human interactions which are interpreted as a process in which interacting parties constantly adapt and change themselves in order to achieve a state of harmonious relationship with others. Likewise, their attitude- - we will cross the bridges when we come to them" (Bhattacharjee \& Zhang, 2011) is very disturbing to Western negotiators who tend to anticipate and plan beforehand.

It has often been said that Chinese negotiators practice win-lose negotiation strategies because they defend interests of their group as detrimental as the deal can be to the other party. This is as much as an inappropriate interpretation of the Chinese way of conducting negotiations as is interpreting the Chinese culture with Western cultural paradigms. The Chinese are not "either/or" people and thus they cannot fit in win-lose negotiation strategies. They are "both/and" people and thus they are closer to win-win negotiation strategies. However, they possess a third level of negotiation which is incarnated by the invisible negotiator which is based on integration - that is — on the "either/and" paradigm, which we will call sustainable negotiation in this paper.

The invisible negotiator is a paradox manager whose role is to bring together what looks to be contradictory and incompatible. Because the action of the invisible negotiator is based on balance as is the interaction between Yin and Yang, his role is to reach harmony by embracing contradictions. If negotiation is needed only when people differ (Cellich \& Jain, 2003), then the role of the invisible negotiator is to embrace these differences and focus on common ground. The new place for international negotiation is where West and East can meet with a more integrated and holistic approach $(\mathrm{Li}, 2016)$. Indeed, the invisible negotiator does not resolve paradoxes, he manages them instead and gets away from polarized positions such as the ones leading to win-win and win-lose strategies.

\section{The Invisible Negotiator and the Yin-Yang Balance}

The role of invisible negotiator can be incarnated by anyone who is able to manage paradoxes between the negotiating parties. Referring to "Tao", no-one "is" the invisible negotiator but someone "becomes" the invisible negotiator during the negotiation process ( $\mathrm{Li}, 2016)$.

The existence of Yin and Yang is based on Confucian values of harmony obtained by a balanced pair of contradictions. Prominent researchers (Li, 2012; 2014; 2016; Li et al., 2012; Fang, 2014; 2011; 2010; 2006; 2003; Fang et al., 2008; Fang \& Faure, 2011; Faure \& Fang, 2008; Faure, 1995; Chen, 1987; Chen, 2011; Chen, 2002; Ghauri \& Fang, 2001; Shi \& Wright, 2003) have been explaining how critical is the understanding and the use of Yin-Yang approach to the analysis of the Chinese culture. Its applicability to international negotiations is paramount for anyone who works with Chinese counterparts. Tendency in Western cultures is to reject contradictions because they are inconsistent with Western beliefs and education. Contradictions mean inconsistency which means suspicious behavior and risky business because contradictions challenge (formal) logic. But the truth can be hidden in paradoxes that could not be solved by logical reasoning. What we see and hear is just a situational reflection of what people are and not of whom they are (Capra, 1976).

$\mathrm{Li}$ (2012) argued that the Yin-Yang balance framework is particularly powerful to measure complex phenomena. The author describes it as an open system meant to accommodate a balance between "either/or" (formal logic) and "both/and" (dialectical logic) paradigms. The formal logic reaches balance by eliminating one of the options, while the dialectical logic reaches balance in bringing extreme poles together with the same 
degree of relevance. But Li (2012), took this discussion to a higher level in suggesting that the "either/and" paradigm reaches balance by integrating the two other ones. In other words, the proposed paradigm includes balance within balance.

It is hardly understandable how and why negotiators should be in opposition to each other while the main reason for them to be negotiating is their interdependence. If negotiation is a basic means of getting what we want from others (Fisher \& Ury, 2011), there should not be any opposition between negotiators. Instead, there should be collaboration, interdependence, and integration. Negotiation is not meant to separate people, but to bring them together. This is exactly the role of the invisible negotiator in China.

In the Yin Yang framework as described by Li (2016), the invisible negotiator is that seed of Yin within Yang and of Yang within Yin which enables both parts to reach balance. The constant back-and-forth movement undertaken by the invisible negotiator from one party to another in order to gather interests, goals, intentions, and ideas allows the Chinese to keep balance throughout the negotiation process. The invisible negotiator is not neutral and assesses constraints and willingness from all parties to get to an honorable deal in giving ideas and suggestions that would place a seed of each other within each other so that their constraints and willingness can reach a sustainable equilibrium. If the balance is not sustainable, there is no harmony; and sooner or later, the negotiators will be stuck in a polarized negotiation outcome. Planting a seed is giving a bit of each negotiator to each negotiator so that they can have a better view of the future together.

As for the Chinese, negotiation is a never-ending process, signing a deal does not mean the end of the negotiation. Rather, it means the start of a life together with perpetual adjustments to be expected and only can be reached if negotiators are part of each other. As negotiation is not perceived as an ephemeral process in China, it embraces paradoxes so that perpetual evolution is envisaged. As such, "win" and "lose" are two opposed sides of the same dimension and competition. Negotiators will "either" sit on one side "or" on the other at the end of the negotiation process. This might give the illusion of a balanced outcome for a negotiation by having one party on each side of the bipolar dimension. But there is no harmony, because it is expected that the side sitting on the "lose" side is unhappy and thereby, the outcome of the negotiation cannot be sustainable. On the other hand, the win-win situation is unbalanced, because all parties are on the same side of the bipolar dimension which is more likely to be an illusion than a real outcome.

The "either/or" paradigm in negotiation focuses on trade-off while the "either/and" paradigm implies synergy and balance. Putting in other words, "win-lose" as an "either/or" strategy focuses on differences and trade-off, while "win-win" as a "both/and" paradigm focuses on similarities. But differences and similarities do not make a negotiation outcome sustainable; it is synergy and complementarity as "either/and" strategy that does it. Indeed, we do not negotiate for obtaining the opposite or the similar. We negotiate for what we need because it complements what we have.

Adopting a Yin-Yang frame is counterintuitive to Westerns who have been raised and trained with bipolar frames, which are based on formal logic and lead them to see the world from the "either/or" (win-lose) perspective. It requires a frog leap paradigm switch for Westerners having been culturally sensitized with static, linear, and non-paradoxical patterns to understand and to adopt the Yin-Yang paradigm.

\section{Negotiating in China Is Managing Paradoxes}

Because the ability to manage paradoxes is inherent in the Chinese culture, Chinese negotiators have a natural ability of bringing together opposed positions and points of view. By putting cards on the table, one by 
one, at the opportune moments and at the appropriate pace, Chinese negotiators move smoothly towards their goals by collecting the agreement of other people involved in the process. Their culturally inherent non-linear, cyclical approach to time (Zhang \& Baker, 2012) allows for more flexibility during the negotiation process than their Western counterparts who view time as racing unutilized if decisions are not being made.

Often disruptive to Western negotiators, time management in China gets along with paradox management. For the non-Chinese negotiators, it takes too long to get to a definite answer and periods of inactivity remain unexplained. Inactivity, as perceived by Westerners can be explained by the invisible action of the invisible negotiator as well as by their understanding of Wu Wei. Fang $(1999$, p. 32) defined this term in a paradoxical way, as "actionless activity", to "act without acting", in a culture where doing nothing is "doing things strategically". The Chinese have this ability to observe before acting, to listen before talking, and to wait for the right moment (context) to take action. The role of the invisible negotiator is to interfere without interference at the right moment, the right way. His ability to observe, to listen, and to understand is the foundation of his role in every negotiation. Waiting for the right moment to take action is rooted in the Chinese stratagems because in the contextual Chinese culture, there is always the right moment to do something and the opportune moment will always come if you are patient enough to wait for it. Changes in the context are seized as the opportunity the Chinese take to keep negotiating the terms of a deal, making it appear like a way of abiding by the new context, just as the "killing with a borrowed knife" stratagem (Fang, 1999, p. 174).

Despite the fact that the role of the invisible negotiator is to reach compromise, his intervention extends negotiations to a longer period of time because it brings more people into the process. Approval of others is crucial to Chinese negotiators, not only because of their collective values but also and mainly because of the hierarchical nature of interactions. Confucian ethos exerts strong influence on behaviour and interactions and it presents a set of ethical and moral rules that drive behaviour, dictate interpersonal relationship, and serve as guidelines in forming individual and societal norms (Huang \& Gove, 2012).

Ultimately, the Chinese are comfortably managing what the non-Chinese avoid - contradictions. Putting in other words, to the Chinese, negotiating is managing paradoxes - it is their natural mode. Paradox management as part of the negotiation process is only an issue vis-à-vis Western binary logic that does not embrace contradictions or ambiguities. To the Chinese, contradictions are not only part of life, but are also and mainly enriching opportunities.

The non-Chinese negotiators' inability to accept and manage paradoxes generates barriers to negotiate with the Chinese, to whom paradoxical management is an integral part of daily life. Additionally, non-Chinese negotiators quickly arrive to deadlocks; because to them, there are only two linear paths to follow-the right one and the left one. In contrast, the Chinese see multiple paths that can be followed to arrive at the same place and they are not linear. Their holistic non-linear vision of things enables them to circumvent difficulties by finding additional alternatives more easily. This ability to explore new paths is highly confusing to the non-Chinese negotiators because they think that the Chinese are making up excuses not to follow the path that they see as being the only one worth following (Chen, 2002; Zhang \& Baker, 2012). There is "invisible great wall" (Fang, 1999) separating Western negotiators from the Chinese negotiators which should not be explained through traditional cultural gaps, but by the inherent ability the Chinese have to manage paradoxes which are not understandable by non-Chinese negotiators.

This inability in predicting the future as a linear sequence from the present leads the Chinese negotiators to review clauses of contracts with considerable frequency, which is perceived by Westerners as a lack of 
reliability to whom trust and reliability are based on consistency. Changes in prior agreements are seen as a lack of consistency. As a result, the invisible negotiator has the power of shaping the future in several unexpected yet accepted ways.

One aspect of the Chinese culture which is destabilizing to the non-Chinese negotiators is the disrespect to rules and laws (Ghauri \& Fang, 2001). Indeed, in the Chinese culture, and thus in their negotiating style, guidance is provided by a set of social values and not by the law. Recourse to law can be considered as bad faith (Bhattacharjee \& Zhang, 2011). Chinese negotiators might infringe the law but not their social norms. They will avoid situations in which there is potential loss of face or any other outcomes that can be detrimental to their group. Therefore, the role of the invisible negotiator is to ensure satisfaction within the groups while compromising with people from outside their group.

Dialectical logic has its roots in Taoism and is a perspective that embraces paradox and contradiction as the very vehicle through which positive change and growth occur (Palich et al., 2002). Following this logic, change is obtained by the tension created between two opposing forces while the absence of this tension results in a lack of evolution. That is why the resolution of contradictions is not consistent with evolution and thus the Chinese spend more time discovering complexities than trying to reduce them. The presence of contradictions is positive but it prevents foreseeing outcomes because future might not be limited to an extension of the current order (Zhang \& Baker, 2012). Unpredictability is a consequence of context which is indeed unpredictable and uncontrollable. Anything can happen in the short term, but the invisible negotiator should make sure that the short run will be shaping up the long run in a favorable way for all those involved in the negotiation.

\section{Towards a New Paradigm for International Negotiation}

The prevalent paradigms in negotiation often highlight opposition, competition, and trade-off which are very consistent with the "either/or" cultural paradigm and clearly reflected in terms such as "counterpart", "the person on other side of the table", "counter argument", "take-it-or-leave-it strategies", "negotiating against someone", just to name a few. No search for harmony is found in such terms. The "win-win" negotiation strategies can be assimilated to "both/and" cultural paradigms, by integrating a more collaborative approach to getting to a deal and searching more for similarities than differences. Yet, no balance is reached because not all parties can win a negotiation. The invisible negotiator in China opens the doors to a more collaborative and balanced negotiation thanks to paradox management. Inspired by the Yin and Yang philosophy, the invisible negotiator incarnates the complementarity needed to reach a balanced agreement between all parties, and makes sure that this balance will be sustainable during the negotiation as much after a first deal is reached. Indeed, the perpetual evolution of negotiations in China makes the process evolve thanks to several milestones which are often materialized by a signature, which enables the negotiations to keep moving forward. The "either/and" paradigm aligns with sustainable negotiation.

The author defines sustainable negotiation as the one based on long-term collaboration. Long term means that signing a deal is not the end of a negotiation. Deal means cooperation, not competition. There are no winners in a deal, just associates. Defining negotiation as a constant and ever evolving process with no apparent end eliminates all possibilities of winning and losing. There is an agreement about working together and the terms of this collaboration are constantly negotiated because adjustments are constantly needed in every collaborative work mainly in cross-cultural settings. 
This never-ending approach to negotiation is inherent in the Chinese culture where there is no clear-cut end to a negotiation. Everything is susceptible to be negotiated at any time, which seems disruptive to Western cultures where the only goal to a negotiation is to sign a deal. The negotiation is then ended and the outcome can be assessed as "either" win "or" lose. Therefore, "win-win" and "win-lose" are misleading terms to a negotiation. So many international negotiations ending up with the need of arbitration and mediation is precisely because negotiators envisage winning. In doing so, they eliminate contradictions, resolve dilemmas, and avoid paradoxes. Yet, paradox management is an indissociable part of international negotiation.

\section{Implications for Theory and Practice}

This paper sheds light on the controversial topic of the Chinese negotiators' behavior in international negotiation. There is still considerable skepticism among businesspeople when it comes to understanding the subtleties of the Chinese negotiating style (Fang, 1999). Expressions such as "business is business" or "Industry is Science; it has nothing to do with Mao Zedong, the Qing Dynasty or Chinese history" (Walsh et al., 1999, p. 75) are often expressed by negotiators who are not sensitive to what is not factual and observable. By obeying to the principles of formal logic, they are unable to see beyond what is visible. As a result, they miss paramount information to move forward in negotiations with the Chinese and are puzzled with their dialectical logic.

Arguably, the existence of duality and paradoxes should not be seen as a problem to work together but as new lenses through which it is more appropriate to understand contextual behavior. As stated by Fang (2006), it is not about managing cultural differences, but about managing cultural learning, cultural change, cultural paradox, and cultural harmony in a multicultural business world. The author recommends seeing culture as a situation-, context-, and time-specific dialectical construct that is critical for strategy formulation and implementation in global business management. Instead of focusing on cultural gaps, international negotiators should focus on how to use cultural differences to energize their relationship and business together.

In the Chinese cosmology, harmony moderates the mutual dependency between the opposite but complementary forces of Yin and Yang, whose perpetual interaction enables the universe to be in the process of constant change (Chen, 1987; Chu, 1974). Similarly, human interactions are interpreted as a process in which the interacting parties constantly adapt and change themselves in order to achieve a state of harmonious relationship with others. Therefore, harmony is the cardinal value in the Chinese culture and establishing a harmonious relationship is the ultimate goal of all human interactions (Chen \& Starosta, 1997). Indeed, the Chinese cultural values are largely formed and created from interpersonal relationships and social orientations because the Confucius doctrine is a basic pillar of Chinese life.

Although assertive behavior and individual initiatives are not encouraged, the Chinese often get what they want from a negotiation, perhaps thanks to the invisible negotiator. To them, self-improvement has to do with continuity. People, life, and elements are in perpetual movement and evolution, just like Yin and Yang. The parties are interdependent and in constant movement in a dynamic process rather than static. But they depend on each other to evolve. They are not contradictory; they are complementary. Together they compensate and balance the strengths and weaknesses of each other. Harmony is obtained thanks to "both". "Neither" of them could do it alone. Ultimately, polarizing negotiation styles in "either" win-win "or" win-lose paradigms are like aiming at disentangling Yin and Yang.

Because negotiation is a collective and evolving process in China, the invisible negotiator intervenes in all phases of the negotiation where he is needed. His role is to make the negotiation move forward. He is the one 
bringing common interests to the light and helping all parties become aware of their respective (and now convergent) interests. The paradoxical aspect of negotiations involving so many people is that the Chinese are both implicit and pragmatic (Faure \& Fang, 2008), and thus, they persevere until they get what they need, without being disrespectful or aggressive towards the people they are negotiating with.

The hierarchical decision-making process inherent in the Chinese culture along with the face saving concerns also justifies the existence of the invisible negotiator. There is high involvement of the Chinese in anything that can entail consequences to many people. The causes and consequences of acts are shared by the community and thus every member of the community has a specific role to play (Faure, 1995). They cannot stay passive and neutral; their duty is to get genuinely involved no matter what the topic is. Although all the people involved in the process might have different perceptions and opinions about the problem to be solved, their strong shared values dictate norms that no-one infringes without being socially punished (Ghauri \& Fang, 2001; Cardon, 2009). These values enable them to participate in any discussion because they represent a framework valid to any professional or social situation. Confucian value system has a strong influence on this dynamics because Confucian ethics is relational, and it propagates morality over utility. It emphasizes dialectical unity between an individual and the group, where individual rights are interpreted in relation to social responsibilities. Individual values could only be realized in the society as a whole; each individual is a part of a social web and as such is in a perpetual state of adjustment of his/her codes of moral behaviour.

China relies more on people than on contracts what are explained by a fragile legal system (Ghauri \& Fang, 2001). While Westerners start the negotiation with a pre-determined contract which they will negotiate and alter as the negotiation evolves, the Chinese negotiate with no contract and build agreements orally, and often thanks to the invisible negotiator. Rather than being an ultimate point of reference, contract is just a milestone within the negotiation process. Business obligations come from relationships and not from legal contracts. A legal contract not only represents a lack of good faith but also does not stand for any formal commitment. The invisible negotiator involves the negotiating parties within a commitment from which trust can be built. Ultimately, it is trust that binds business partners rather than contracts (Bhattacharjee \& Zhang, 2011).

\section{Conclusions}

Understanding paradox management and invisible influences in negotiation is paramount to all those who do business with the Chinese. The invisible negotiator unfolds the negotiation process as it evolves constantly bringing new inputs to all parties. Such inputs are not necessarily facts. They can be perceptions, interpretations, anecdotes, and subjective information which can count more than objective facts. Often, objective facts are omitted when they can potentially make someone lose face or lead to a conflicting situation. They are replaced with an interpretation of the facts which can sound more sympathetic to the people involved in the negotiation. As the invisible negotiator is the one providing such inputs, no-one will search for the sources of the information provided by him in order to check authenticity. Protecting relationships and face is often more important than reporting objective facts and therefore, the invisible negotiator is the one who saves everyone's face by acting as an intermediary. In other words, he is the one who stirs everything towards balance and harmony. In China, people are better valued and trust is built more quickly if the foreign negotiator is introduced by a third party. This person might become the invisible negotiator. He might not be seen at the table of negotiations but will be present during the whole process behind the curtains. 
As a new business context emerges, the author suggests that there is more subtlety in the Chinese culture than what is observed. The author's paper has revealed important cultural factors which exert profound influence on the negotiations' dynamic, namely paradox management and the existence of the invisible negotiator as the key forces in the Chinese negotiation process.

\section{References}

Bhattacharjee, A., \& Zhang, L. (2011). Cultural toolkit for Indians desirous of doing business in China. VIKALPA, 36(2), 59-79. Capra, F. (1976). The Tao of physics. Boulder, Colorado: Bantam Books.

Cardon, P. (2009). A model of face practices in Chinese business culture: Implications for Western businesspersons. Thunderbird International Business Review, 51(1), 19-36.

Cellich, C., \& Jain, S. C. (2003). Global business negotiations: A practical guide. Mason, Ohio: Thompson.

Chen, D. C. (1987). Confucius thoughts. Taipei, Taiwan: ChengChuong.

Chen, G. M. (2001). Towards transcultural understanding: A harmony theory of Chinese communication. In Y. H. Milhouse, M.

K. Asante, and P. Nwosu (Eds.), Transculture realities: Interdisciplinary perspectives on cross-cultural relations (pp. 55-70). Thousand Oaks, CA: Sage.

Chen, G. M., \& Starosta, W. J. (1997). Chinese conflict management and resolution: Overview and implications. Intercultural Communication Studies, 7, 1-16.

Chen, M. J. (2002). Transcending paradox: The Chinese "middle way" perspective. Asia Pacific Journal of Management, 19, 179-199.

Chu, S. (1974). The interpretation of I Ching. Taipei, Taiwan: WenHua.

Chuah, S. H., Hoffman, R., \& Larner, J. (2014). Chinese values and negotiation behavior: A bargaining experiment. International Business Review, 23, 1203-1211.

Eiteman, D. K. (1990). American executives' perceptions of negotiating joint ventures with the People's Republic of China: Lessons learned. Columbia Journal of World Business, 25(4), 59-67.

Fang, T. (1999). Chinese business negotiating style. International Business Series. Thousand Oaks, CA: Sage.

Fang, T. (2003). A critique of Hofstede's fifth national culture dimension. International Journal of Cross Cultural Management, 3(3), 347-368.

Fang, T. (2006). From "onion" to "ocean": Paradox and change in national cultures. International Studies of Management \& Organization, 27(4), 71-90.

Fang, T. (2010). Asian management research needs more self-confidence: Reflection on Hofstede (2007) and beyond. Asia Pacific Journal of Management, 27, 155-170.

Fang, T. (2011). Yin Yang: A new perspective on culture. Management and Organization Review. Pp. 1-26.

Fang, T. (2014). Understanding Chinese culture and communication: The Yin Yang approach. In B. Gehrke and M. C. Claes (Eds.), Global leadership practices (pp. 171-187). London: Palgrave Macmillan.

Fang, T., \& Faure, G. O. (2011). Chinese communication characteristics: A Yin Yang perspective. International Journal of Intercultural Relations, 35(2011), 320-333.

Fang, T., Worm, V., \& Tung, R. L. (2008). Changing success and failure factors in business negotiations with the PRC. International Business Review, 17, 159-169.

Faure, G. O. (1995). Nonverbal negotiation in China: Cycling in Beijing. Negotiation Journal, 11(1), 11-17.

Faure, G. O., \& Fang, T. (2008). Changing Chinese values: Keeping up with paradoxes. International Business Review, 17, $194-207$.

Fisher, R., \& Ury, W. (2011). Getting to yes. New York: Pinguin.

Ghauri, P., \& Fang, T. (2001). Negotiating with the Chinese: A socio-cultural analysis. Journal of the World Business, 36(3), 303-325.

Graham, J. L., \& Hernandez Requejo, W. (2009). Managing face-to-face international negotiations. Organizational Dynamics, $38(2), 167-177$.

Hall, E. (1976). Beyond culture. New York: Anchor.

Hofstede, G. (1984). Culture's consequences. New York: Sage.

Hofstede, G., \& Hofstede, G. J. (2005). Cultures and organizations: Software of the mind. New York: McGraw-Hill.

Huang, G., \& Gove, M. (2012). Confucianism and Chinese families: Values and practices in education. International Journal of Humanities and Social Science, 2(3), 10-12. 
Karsaklian, E. (2014). The intelligent international negotiator. New York: Business Expert Press.

Leung, T. K. P., Chan, R. Y. K., Lai, K. H., \& Ngai, E. W. T. (2011). An examination of the influence of guanxi and xinyong (utilization of personal trust) on negotiation outcome in China: An old friend approach. Industrial Marketing Management, 40, 1193-1205.

Lewiki, R. J., Saunders, D. M., \& Barry, B. (2011). Essentials of negotiation. New York: McGraw-Hill.

Lewis, R. (2006). When cultures collide. London: Nicholas Brealey.

Lewis, R. (2012). When teams collide. London: Nicholas Brealey.

Li, P. P. (2012). Toward an integrative framework of indigenous research: The geocentric implications of Yin-Yang balance. Asia Pacific Journal of Management, 29, 849-872.

Li, P. P. (2014). The unique value of Yin-Yang balancing: A critical response. Management and Organization Review, 10, 321-332.

Li, P. P. (2016). Global implications of the indigenous epistemological system from the East: How to apply Yin-Yang balancing to paradox management. Cross Cultural \& Strategic Management, 23(1), 1-39.

Li, P. P., Leung, K., Chen, C. C., \& Luo, J. D. (2012). Indigenous research on Chinese management: What and how. Management and Organization Review, 8(1), 7-24.

Nakamura, H. (1964). Ways of thinking of Eastern people. Honolulu: East-West Center Press.

Osman-Gani, A., \& Tan, J. S. (2002). Influence of culture on negotiation styles of Asian managers: An empirical study of major cultural/ethnic groups in Singapore. Thunderbird International Business Review, 44(6), 819-839.

Palich, L. E., Carini, G. R., \& Livingstone, L. P. (2002). Comparing American and Chinese negotiating styles: The influence of logic paradigms. Thunderbird International Business Review, 44(6), 777-798.

Rivers, C. (2009). Negotiating with the Chinese: EANT's and all. Thunderbird International Business Review, 51(5), 473-489.

Saee, J. (2008). Best practice in global negotiation strategies for leaders and managers in the 21 st century. Journal of Business Economics and Management, 9(4), 309-318.

Shi, X., \& Wright, P. C. (2003). The potential impacts of national feelings on international business negotiations: A study in the China context. International Business Review, 12, 311-328.

Stewart, S., \& Keown, C. F. (1989). Talking with the dragon: Negotiating in the People's Republic of China. Columbia Journal of World Business, 24(3), 68-72.

Tian, X. (2007). Managing international business in China. Sydney: Cambridge.

Trompenaars, F., \& Hampden-Turner, C. (2006). Riding the waves of culture. London: Nicholas Brealey.

Walsh, J. P., Wang, E., \& Xin, K. R. (1999). Same bed, different dreams: Working relationships in Sino-American joint ventures. Journal of the World Business, 34(1), 69-93.

Zhang, H., \& Baker, G. (2012). Think like Chinese. New York: The Federation Press. 